\title{
Sección especial \\ Documentos del Seminario Fondo de Investigación UCA 2012-13
}

\section{Presentación}

El Fondo de Investigación de la Universidad Centroamericana "José Simeón Cañas" (Fondo de Investigación UCA) se creó en 2011, para estimular y fortalecer las capacidades investigativas de los académicos de la universidad, para que a partir de allí se tuviera un impacto importante en iluminar los principales problemas que afectan a El Salvador y la región centroamericana. Para cumplir dicho propósito, se lanzó la primera convocatoria en 2012, en la cual concursaron proyectos que respondieran a las líneas de investigación formuladas en el plan estratégico de la universidad y que, de manera preferencial, implicasen la colaboración de distintas unidades académicas o de proyección social de la UCA. Estos proyectos fueron evaluados y examinados por una comisión de investigadores nombrada para tal propósito. Se seleccionaron un total de once proyectos provenientes de las áreas de Ingeniería, Ciencias Sociales y Humanidades.

Durante los días 3 y 4 de octubre de 2013, se realizó el Seminario Fondo de Investigación UCA 2012-13, donde se expusieron a la comunidad universitaria y a la sociedad salvadoreña los resultados de los once proyectos que recibieron financiamiento para la primera convocatoria del Fondo de Investigación. Con estas intervenciones se espera abrir un debate para pensar estrategias que incrementen la actividad investigativa a nivel universitario en El Salvador.

Durante la inauguración, pronunciaron sus palabras el rector de la UCA, Andreu Oliva S. J., y el Vice-Ministro de Educación, Héctor Samour. Incluimos los textos de sus intervenciones en la presente sección. En jornadas subsiguientes, el seminario contó con la participación de la Dra. Patricia Fumero, de la 
Universidad de Costa Rica, quien compartió la experiencia de investigación de su universidad en la ponencia "Los retos históricos de la Universidad de Costa Rica en el campo de la investigación". Asimismo, se dio un conversatorio sobre la investigación en el país, donde expusieron sus puntos de vista el Dr. Héctor Dada, economista; el Dr. Francisco Chávez, ingeniero; y el Maestro Carlos Lara Martínez, antropólogo.

En el presente número de Realidad, incluimos los resúmenes de los proyectos presentados en el Seminario. 